\title{
The impact of laparoscopic adrenalectomy on renal function. Results of a prospective randomised clinical trial
}

\author{
Tomasz Kozłowski', Alicja Rydzewska-Rosołowska², Janusz Myśliwiec ${ }^{3}$, Barbara Choromańska ${ }^{1}$, \\ Piotr Wojskowicz', Jacek Dadan', Marta Łukaszewicz-Zając ${ }^{4}$, Barbara Mroczko", Piotr Myśliwiec ${ }^{1}$ \\ ${ }^{1} 1^{\text {st }}$ Department of General and Endocrine Surgery, Medical University of Bialystok, Bialystok, Poland \\ ${ }^{2} 2^{\text {nd }}$ Department of Nephrology and Hypertension, Medical University of Bialystok, Bialystok, Poland \\ ${ }^{3}$ Department of Nuclear Medicine, Medical University of Bialystok, Bialystok, Poland \\ ${ }^{4}$ Department of Biochemical Diagnostics, Medical University of Bialystok, Bialystok, Poland
}

\begin{abstract}
Introduction: Laparoscopic adrenalectomy is the gold standard management of benign adrenal masses and isolated metastases to adrenal glands. Two techniques of endoscopic adrenalectomy: lateral transperitoneal approach (LTA) and posterior retroperitoneal approach (PRA) seem to be equally safe and effective. Recent studies suggest advantages of PRA over LTA in terms of lower intensity of postoperative pain, shorter hospital stay, faster recovery, and lower early morbidity. However, PRA involves high insufflation pressure of $\mathrm{CO}_{2}$ within a limited retroperitoneal space.

The aim of our study was to prospectively assess the effect of LTA versus PRA laparoscopic adrenalectomies on renal function.

Material and methods: We randomly assigned patients referred for unilateral adrenalectomy to either LTA $(n=33)$ or PRA $(n=44)$. The inclusion criteria were: hormonal activity and/or tumour diameter $>4 \mathrm{~cm}$ and/or suspicion of metastasis to adrenal gland. The exclusion criteria comprised: tumours $>8 \mathrm{~cm}$, results of imaging studies suggesting primary invasive malignancy, and refusal to undergo randomisation. The patients were prospectively followed for a minimum of six months. Serum creatinine, cystatin C, and urinary neutrophil gelatinase-associated lipocalin (NGAL) were measured preoperatively and at postoperative days: 1, 7, and 30 .

Results: We found increased concentrations of urinary NGAL at day 1 following laparoscopic adrenalectomy using PRA, as compared to LTA. Patients undergoing right-sided PRA had increased creatinine concentrations, as compared to left-sided PRA. Patients with aldosterone-producing adenoma had decreased preoperative eGFR as compared to subjects with non-functioning incidentaloma. NGAL increased significantly in this group postoperatively. All the disturbances normalised within one month postoperatively.

Conclusions: Renal function impairment after PRA may result from compression of inferior vena cava by high retroperitoneal pressure during right-sided adrenalectomy. Despite the transient character of the observed abnormalities, we suggest that patients with high risk of acute kidney injury may benefit from an alternative technique of adrenalectomy using LTA. (Endokrynol Pol 2019; 70 (5): 409-416)

Key words: adrenalectomy; acute kidney injury; NGAL; creatinine; cystatin C
\end{abstract}

\section{Introduction}

Adrenal masses belong to the most prevalent of all tumours found in humans. Reported in approximately $3 \%$ of middle-aged adults, their prevalence increases to $10 \%$ in the elderly [1-3]. Only tumours with hormonal activity or risk of malignancy require surgical treatment [4-7]. Minimally invasive techniques are gaining acceptance in the management of many diseases, including adrenal pathologies [8-10]. Laparoscopic adrenalectomy is now the gold standard of surgical treatment for benign adrenal masses [11]. Currently, two approaches are recommended for laparoscopic adrenalectomy: lateral transperitoneal approach (LTA) and posterior retroperitoneal approach (PRA) [12]. Both LTA and PRA are associated with very low rates of perioperative complications. For most adrenal lesions requiring surgical treatment, adrenalectomy can be performed safely and effectively with either LTA or PRA approach. The choice usually depends on the surgeon's preference; however, an increasing volume of data suggest that PRA is superior to LTA due to shorter operative time, lower blood loss, lower postoperative pain, faster recovery, improved cost-effectiveness, lower morbidity, abolished risk of surgical site herniation, and shorter hospital stay [11-13]. Nevertheless, PRA requires much higher pressure of $\mathrm{CO}_{2}$ insufflation as compared to LTA ( 25 vs. $12 \mathrm{~mm} \mathrm{Hg}$ ). As a consequence, renal veins and inferior vena cava during right-sided PRA are compressed for as long as 30-150 minutes, depending on the difficulty of the operation and the surgeon's experience [13-15]. In some patients after adrenalectomy 
a deterioration of renal function has been reported (when an aldosterone-producing adenoma was identified) [16-18]. According to our knowledge, the impact of laparoscopic adrenalectomy on renal function has not yet been studied in a prospective randomised trial.

The aim of this study was to compare prospectively the impact of different techniques of laparoscopic adrenalectomy (either LTA or PRA) on renal function.

\section{Material and methods}

\section{Study design}

We assessed prospectively all patients referred for elective unilateral adrenalectomy between February 2015 and June 2018 for eligibility in this trial (Fig. 1). Inclusion criteria were: hormonal, tumour diameter $>4 \mathrm{~cm}$, and/or suspicion of metastasis. Exclusion criteria were: tumours $>8 \mathrm{~cm}$ (larger tumours cannot be operated by PRA due to limited space), primary invasive malignancy suspicion based on imaging studies, and refusal to undergo randomisation. We randomly assigned eligible patients to either LTA or PRA. The sample size was calculated on the assumption that a $20 \%$ change in studied parameters should be clinically relevant. To ascertain that the study has $90 \%$ power, 24 patients would be required in each arm. Assuming possible losses to follow-up we decided to include at least 33 patients in each group.

\section{Preoperative workup}

Each patient had spiral computed tomography with contrast according to adrenal protocol. Hormonal function was assessed with urinary metoxycatecholamines, ACTH, diurnal cortisol, dexamethasone suppression test, DHEAS, serum aldosterone and renin activ- ity, and ionogram. In patients with suspicion of metastatic adrenal masses, positron emission tomography with 18-fluorodeoxyglucose was used to rule out disseminated disease.

All patients with suspected pheochromocytoma were prepared for the operation for 10-14 days with alpha-adrenergic antagonists, and for at least two days before surgery beta-adrenergic blockade was added. Primary hyperaldosteronism patients obtained potassium-sparing diuretics and electrolyte supplementation preoperatively. All patients were admitted to hospital one day before surgery. Low-molecular-weight heparin (Enoxaparin $40 \mathrm{mg}$ ) was administered subcutaneously 12 hours preoperatively. Prophylactic antibiotic (1000 mg cephazolin) was infused intravenously within half an hour before the operation. All patients gave informed consent for participation in the study. The study was approved by the University Ethics Committee and obtained Study Registry Number R-I-002/66/2015.

\section{Interventions}

All patients underwent unilateral total adrenalectomy under general anaesthesia. All the operations were performed by a single surgeon with experience in performing laparoscopic adrenalectomies by both approaches: LTA and PRA. For LTA the lateral decubitus position was used. Pneumoperitoneum was created using a Veres needle for left LTA adrenalectomy and Hasson technique for right LTA adrenalectomy, and the pressure of $\mathrm{CO}_{2}$ was set at $12 \mathrm{~mm} \mathrm{Hg}$ for both. For left LTA three trocars (two $10 \mathrm{~mm}$ trocars and a $5 \mathrm{~mm}$ trocar) were inserted below the costal arch. For all right LTA and selected left LTA adrenalectomies an additional $5 \mathrm{~mm}$ trocar was placed in the mid-axillary line for liver retraction. A $30^{\circ}$ laparoscope was used in all patients. After inspection and freeing of adhesions, for left LTA we mobilised the splenic flexure of the colon and the spleen and for right LTA - the right lobe of the liver. Left renal vein or inferior vena cava were identified, respectively. The main adrenal vein was ligated using a bipolar advanced haemostatic instrument,

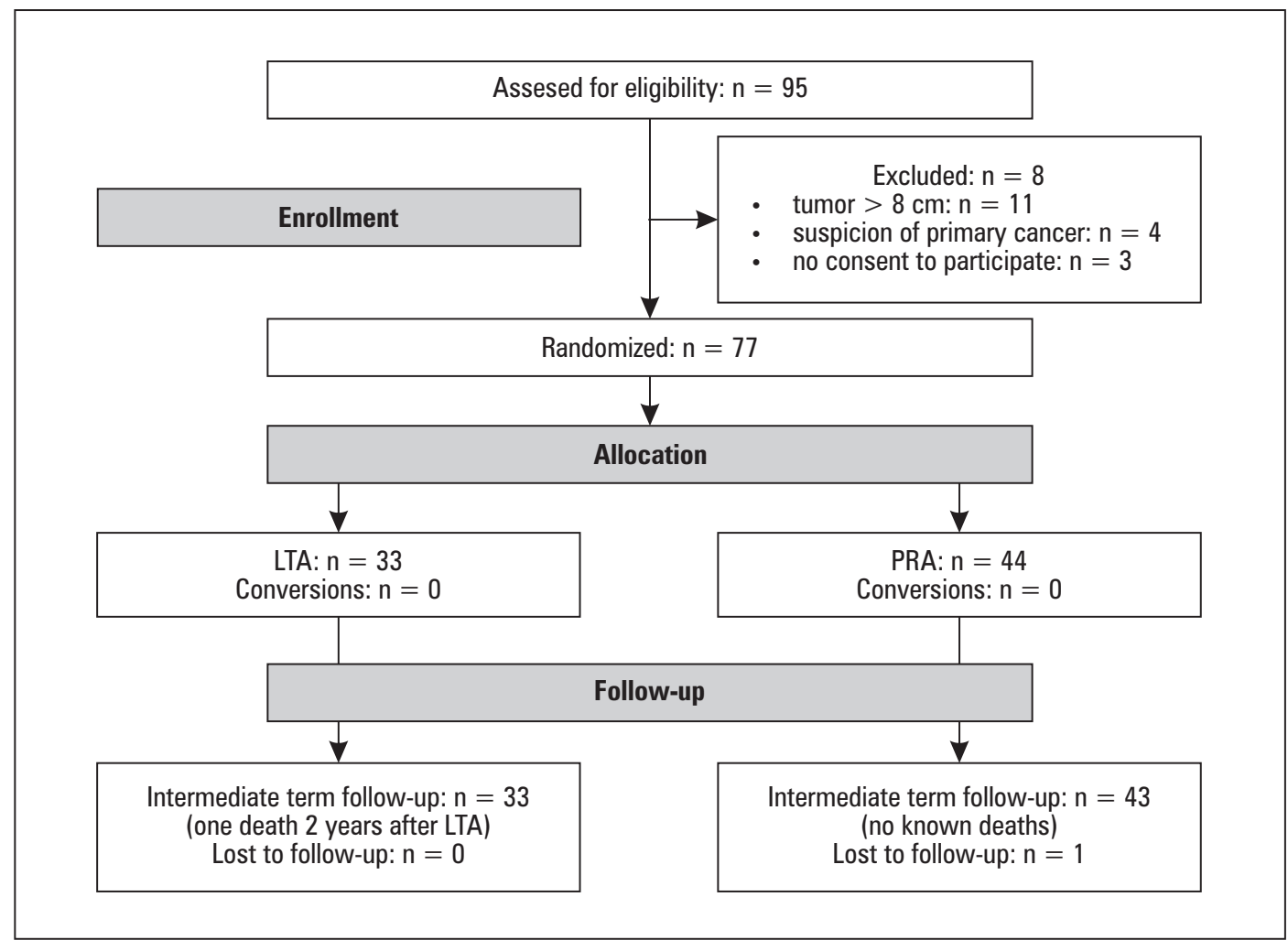

Figure 1. Flow diagram of the study (accepted for publication in Videosurgery and Other Minimally Invasive Techniques) 
and so were all remaining vessels. Polymer clips were used only for vessels $7 \mathrm{~mm}$ in diameter. After resection with surrounding fat, the adrenal gland was placed in an extraction bag and morcellated when the edges of the extraction bag were $2 \mathrm{~cm}$ outside. Control of the operative field and aspiration of any visible blood was performed. The bed of the adrenal gland was flushed with $0.9 \%$ saline and aspirated. All wounds $10 \mathrm{~mm}$ or larger were closed with a laparoscopic port site closure device. Interrupted sutures were used for wound closure, and sterile gauze dressing was applied. For PRA a prone position was used with hip and knee joints flexed. The first incision was performed at the tip of the $12^{\text {th }}$ rib. Blunt scissors were used to penetrate the retroperitoneal space. Under digital control three trocars $(12,10$, and $5 \mathrm{~mm})$ were introduced into the retroperitoneal space. $\mathrm{CO}_{2}$ was insufflated at a pressure of $25 \mathrm{~mm} \mathrm{Hg}$. A $30^{\circ}$ laparoscope was used. Gerota's fascia was opened bluntly to identify the upper pole of the kidney. For right PRA the inferior vena cava was exposed to dissect the adrenal vein safely. For left PRA, due to the longer segment of adrenal vein, exposure of the left renal vein was not necessary. Further steps were similar to LTA. Skin and subfascial space were anaesthetised with $10 \mathrm{~m}$ $0.5 \%$ Bupivacain for postoperative analgesia. Drains were not used — this approach has previously been confirmed to be safe [19].

\section{Postoperative management}

All patients were offered standard postoperative analgesia and were encouraged to drink fluids and ambulate as early as two hours postoperatively. Starting from the next morning, a full diet was recommended. Routinely the patients were discharged home 24 hours postoperatively. All patients with hypercortisolism obtained postoperative hydrocortisone in gradually decreasing doses according to clinical assessment and serum cortisol concentrations. The patients were followed-up in the outpatient department.

\section{Laboratory measurements}

Fasting venous blood and urine were taken preoperatively (Day 0 ), in the morning of the first postoperative day (Day 1), and one week (Day 7) and one month (Day 30) after the procedure. After clot formation the blood was centrifuged for 10 minutes at $1000 \mathrm{~g}$ and stored at $-80^{\circ} \mathrm{C}$ until final analyses. For the analysis of creatinine, the enzymatic method was used. Serum cystatin $C$ was assayed by the immunoturbidimetric method. Neutrophil gelatinase-associated lipocalin (NGAL), also known as lipocalin-2, is an adipokine (adiposederived cytokine) transporting small lipophilic molecules, such as steroids and lipopolysaccharides. It has been reported to play roles in the induction of apoptosis in haematopoietic cells, transport of fatty acids and iron, modulation of inflammation, immunity, and metabolic homeostasis. Recently, NGAL has emerged as an early marker of renal impairment [20,21]. NGAL was measured in urine by chemiluminescent microparticle immunoassay (CMIA). All parameters were determined using ARCHITECT 8200ci.

\section{Statistical analysis}

Statistica 13 for Windows (StatSoft, Krakow, Poland) software was used. Data distribution was verified using Shapiro-Wilk test. Assessment with Kruskal-Wallis ANOVA test was performed for multiple independent groups and Mann-Whitney test for two independent samples. Dependent variables were compared using Wilcoxon test. For correlations we used Spearman test. We considered $\mathrm{p}<0.05$ as significant.

\section{Results}

We assessed 95 patients for eligibility in the trial. Eighteen patients were excluded for reasons shown in Figure 1. Eligible patients were randomly assigned to undergo either LTA (33 patients) or PRA (44 patients), and all of them completed at least six months of follow-up. Demographic data did not differ significantly between the groups (Tab. I). Sixty-two out of 77 patients were on hypotensive medication. The average number of drugs to treat hypertension was $1.94 \pm 1.49$, whereas at completion of follow-up it decreased to $1.38 \pm 1.28$. There were no patients fulfilling preoperative criteria of chronic kidney disease [22]. The clinical outcomes of operations were accepted for publication in Videosurgery and Other Minimally Invasive Techniques. In short, both LTA and PRA proved safe and effective. Operative time tended to be longer for pheochromocytoma and malignant tumours, reflecting higher levels of difficulty in both clinical settings. Nevertheless, the safety

Table I. Patients' characteristics

\begin{tabular}{|c|c|c|c|}
\hline & $\begin{array}{c}\text { LTA } \\
(\mathrm{n}=\mathbf{3 3})\end{array}$ & $\begin{array}{c}\text { PRA } \\
(n=44)\end{array}$ & p value \\
\hline \multicolumn{4}{|l|}{ Age [years] } \\
\hline Mean \pm SD & $61.2 \pm 8.3$ & $59.3 \pm 10.2$ & NS \\
\hline$(\min -\max )$ & $(44-84)$ & $(32-81)$ & \\
\hline \multicolumn{4}{|l|}{ Gender } \\
\hline Male & $13(39 \%)$ & $21(48 \%)$ & NS \\
\hline Female & $20(61 \%)$ & $23(52 \%)$ & \\
\hline \multicolumn{4}{|l|}{ BMI $\left[\mathrm{kg} / \mathrm{m}^{2}\right]$} \\
\hline mean \pm SD & $30.1 \pm 6$ & $29.1 \pm 5.2$ & NS \\
\hline $\begin{array}{l}\text { Number of hypotensive } \\
\text { drugs }\end{array}$ & $2.0 \pm 1.53$ & $1.89 \pm 1.82$ & NS \\
\hline ASA median (min-max) & $3(2-4)$ & $3(2-4)$ & NS \\
\hline $\begin{array}{l}\text { Tumour size: median } \\
\text { (min-max) }\end{array}$ & $4.1(1.5-7.5)$ & $4.0(0.8-7.5)$ & NS \\
\hline Location & & & NS \\
\hline Right side & $11(33 \%)$ & $18(40 \%)$ & \\
\hline Left side & $22(67 \%)$ & $26(60 \%)$ & \\
\hline Hormonal diagnosis & & & NS \\
\hline Pheochromocytoma & $4(12 \%)$ & $9(20 \%)$ & \\
\hline Cushing's disease & $5(15 \%)$ & $3(7 \%)$ & \\
\hline Conn's disease & $2(6 \%)$ & $4(9 \%)$ & \\
\hline Nonfunctioning tumour & $22(67 \%)$ & $28(64 \%)$ & \\
\hline Pathological diagnosis & & & NS \\
\hline Pheochromocytoma & $2(6 \%)$ & $5(11 \%)$ & \\
\hline Adenoma & $27(82 \%)$ & $31(70 \%)$ & \\
\hline Nodular hyperplasia & $1(3 \%)$ & $2(5 \%)$ & \\
\hline Myelolipoma & $1(3 \%)$ & $1(2.3 \%)$ & \\
\hline Ganglioneuroma & $1(3 \%)$ & $1(2.3 \%)$ & \\
\hline Cancer metastasis & $1(3 \%)$ & $3(7 \%)$ & \\
\hline Lymphangioma & $0(0 \%)$ & $1(2.3 \%)$ & \\
\hline
\end{tabular}

LTA — lateral transperitoneal approach; PRA — posterior retroperitoneal approach SD — standard deviation; min-max — full range (minimum-maximum); NS — not significant; BMI — body mass index; ASA — operative risk according to the American Society of Anaesthesiologists 
and efficacy of a minimally invasive approach to both pheochromocytoma and selected adrenal malignancies have previously been confirmed [23, 24]. In our material there were no conversions, no blood transfusions, or major complications within 30 days postoperatively. The only complication observed was pain continuing beyond seven days in four patients from the LTA and PRA groups. No medications were added postoperatively, other than analgesics, low-molecular-weight heparins, or hydrocortisone in patients with preoperative hypercortisolism.

Initial and postoperative creatinine concentrations were similar in LTA and PRA groups (Tab. II). However, the subgroup analysis showed that patients submitted to right adrenalectomy by PRA had increased serum concentrations of creatinine at postoperative day 1 (on average by $20 \%$ ) as compared to left adrenalectomy by the same approach $(\mathrm{p}<0.05)$ (Tab. II, Fig. 2). At the same time, at day 1 patients who underwent right adrenalectomy by PRA had higher creatinine concentrations than those assessed at day $0(p<0.05)$ (Tab. II, Fig. 2). At further time points, this difference was no longer significant as compared to the preoperative values and the patients with left adrenalectomy by PRA (Tab. II, Fig. 2). Finally, at day 30 the mean values returned to preoperative values.

The serum concentrations of cystatin $C$ tended to follow creatinine levels; however, the differences did not reach statistical significance (Tab. II, Fig. 3). Nevertheless, we found a high positive correlation between cystatin $C$ and creatinine serum concentrations assessed at postoperative day $1(R=0.7)$.

Urinary NGAL concentrations increased significantly after adrenalectomies performed using PRA as compared to LTA at postoperative day 1 (Tab. II, Fig. 4). The difference between preoperative measurements and those taken 24 hours later reached on average $58 \%(\mathrm{p}<0.001)$ and were greater after right than left adrenalectomies by PRA $(+97 \%-\mathrm{p}<0.001$ vs. $+33 \%$ $-p>0.05$ ) (Tab. II, Fig. 4). A week after the operation, urinary NGAL concentrations decreased significantly as compared to the measurements at day 1 in the whole PRA group ( $p<0.001)$, left PRA ( $p<0.05)$, and right PRA ( $\mathrm{p}<0.01)$ (Tab. II, Fig. 4). Thirty days postoperatively the differences of preoperative levels and differences between groups were no longer significant.

\section{Discussion}

Ours is a pioneering study to compare the two most common techniques of laparoscopic adrenalectomy: LTA versus PRA, with regard to renal function. In this trial we demonstrated for the first time that PRA may cause transient impairment of renal function, as op-

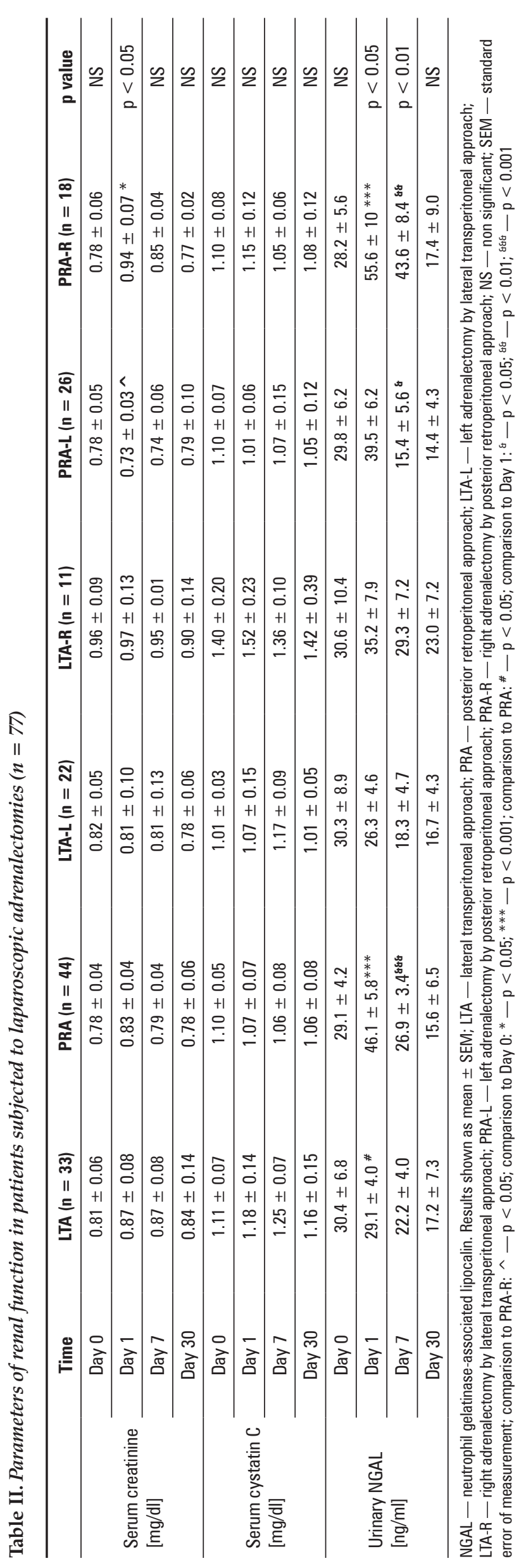




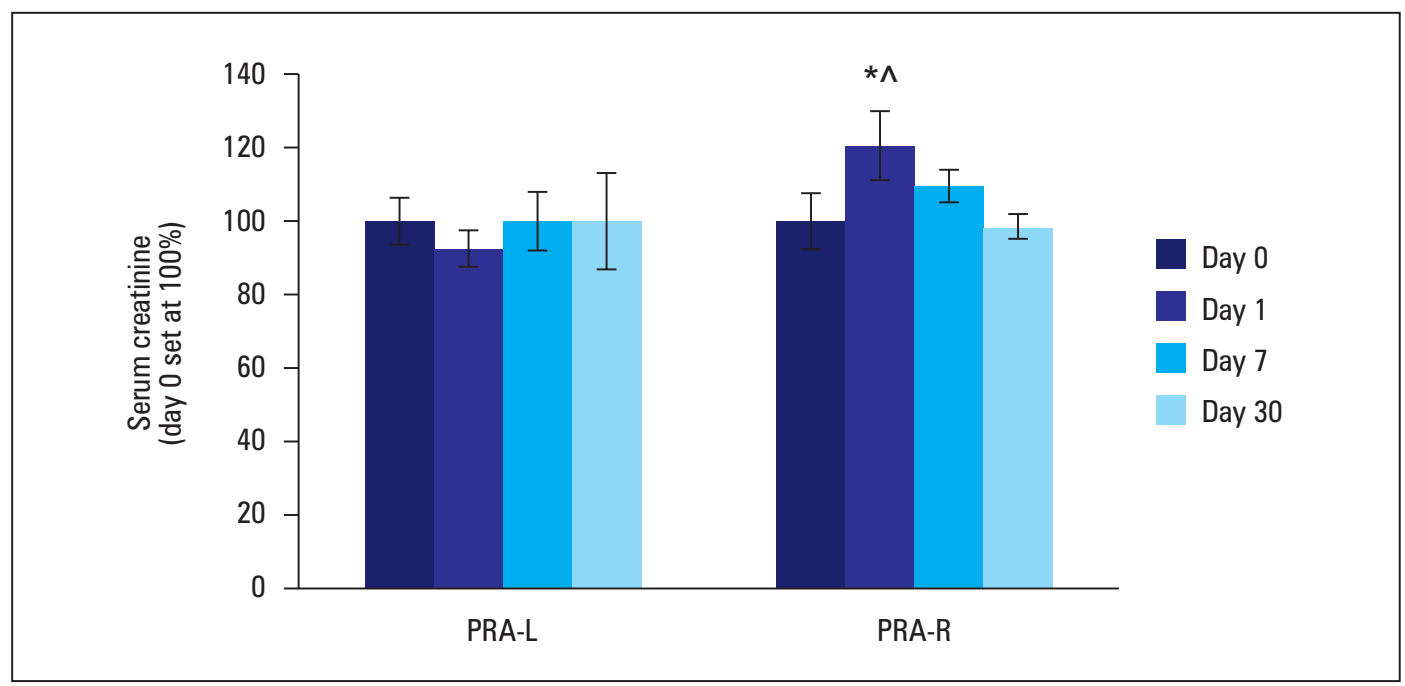

Figure 2. Serum concentrations of creatinine in patients operated using posterior retroperitoneal approach: PRA-L — left adrenalectomy by posterior retroperitoneal approach; PRA-R — right adrenalectomy by posterior retroperitoneal approach. The mean concentration at day 0 was set at 100\% separately for LTA and PRA groups to better visualise the differences between preoperative and postoperative measurements. Data shown as mean \pm standard error of measurement; comparison to day $0:{ }^{*}-p<0.05$, comparison to PRA-L day 1: $\hat{\imath}-p<0.05$

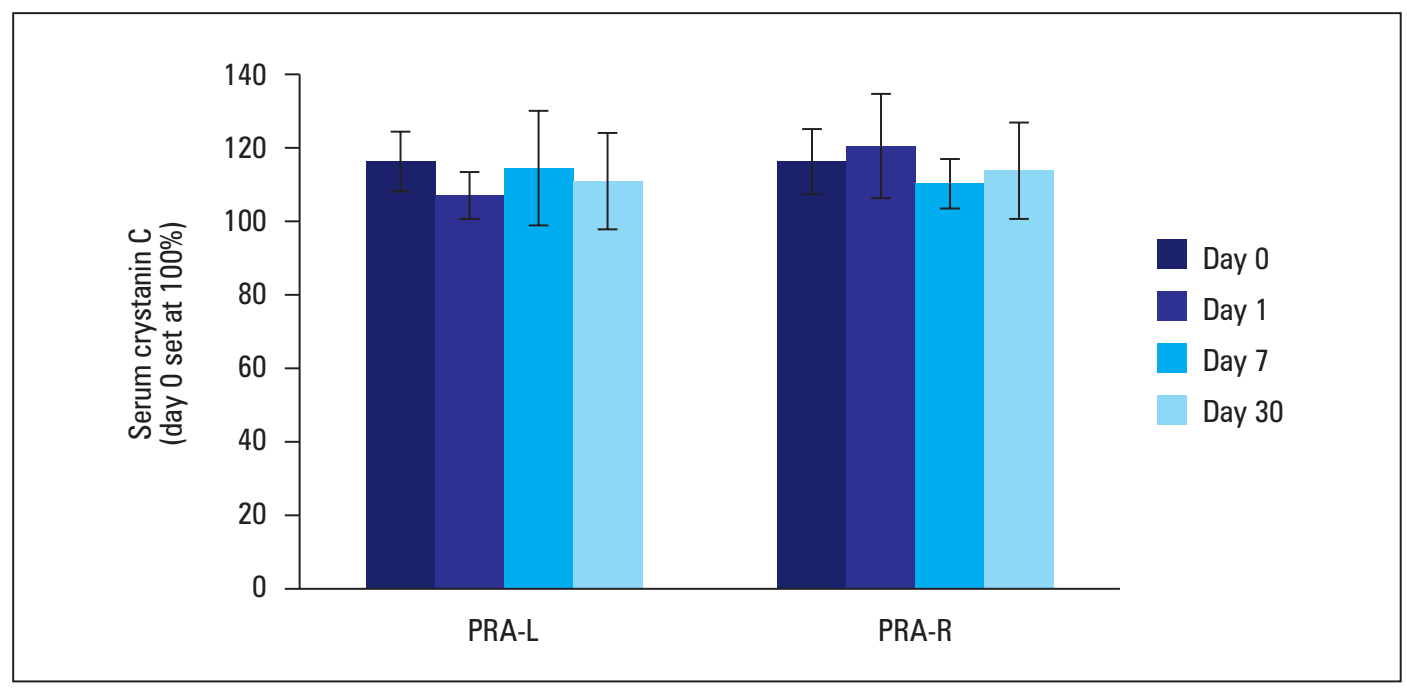

Figure 3. Serum concentrations of cystatin $C$ in patients operated using posterior retroperitoneal approach: PRA-L — left adrenalectomy by posterior retroperitoneal approach; PRA-R - right adrenalectomy by posterior retroperitoneal approach. The mean concentration at day 0 was set at 100\% separately for LTA and PRA groups to better visualise the differences between preoperative and postoperative measurements. Data shown as mean \pm standard error of measurement

posed to LTA. This has been witnessed by increased urinary NGAL concentrations at the first postoperative day (Tab. II, Fig. 4).

Urinary NGAL has been reported to be the most sensitive maker of acute kidney injury when assessed 24 hours postoperatively, superior to both creatinine and cystatin C [19]. Indeed, in our study urinary NGAL concentrations showed the highest increases at day 1 postoperatively as compared to preoperative values in patients after PRA adrenalectomy (Tab. II). Even though PRA patients had significantly greater NGAL levels than LTA, subgroup analysis showed that only subjects after right PRA had significant postoperative increase in urinary NGAL (Tab. II, Fig. 4). Interestingly, preoperative urinary NGAL concentrations tended to be greater than at one month postoperatively. This phenomenon might be associated with relative dehydration [25] of patients at admission to hospital due to fasting and administrative delays.

We found in a subgroup analysis that right-sided adrenalectomies by PRA resulted in a greater extent of renal function impairment than left-sided opera- 


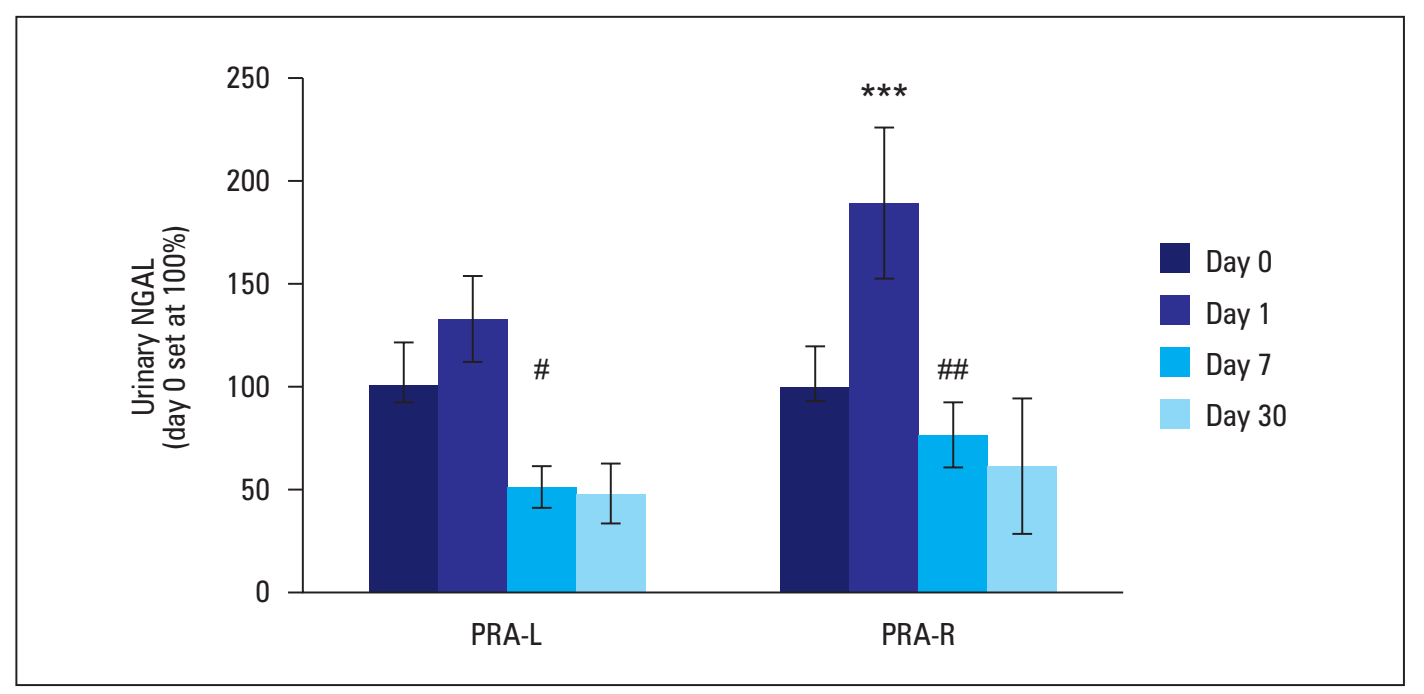

Figure 4. Urinary concentrations of neutrophil gelatinase-associated lipocalin (NGAL) in patients operated using posterior retroperitoneal approach: $P R A-L$ — left adrenalectomy by posterior retroperitoneal approach; $P R A-R$ — right adrenalectomy by posterior retroperitoneal approach. The mean concentration at day 0 was set at 100\% separately for LTA and PRA groups to better visualise the differences between preoperative and postoperative measurements. Data shown as mean \pm standard error of measurement; comparison to day 0:

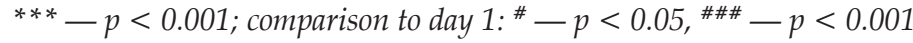

tions. This was shown by both increased NGAL and creatinine concentrations (Tab. II, Fig. 2, 4).

Creatinine is thought to be a universal index of kidney function. However, its serum concentration depends not only on glomerular filtration rate, but also on active secretion by the distal tubules [26]. A possible explanation of greater creatinine concentrations in serum after right compared to left adrenalectomy by PRA (Tab. II, Fig. 2) is compression of the inferior vena cava by the high pressure of retroperitoneal $\mathrm{CO}_{2}$ insufflation during PRA ( $25 \mathrm{~mm} \mathrm{Hg}$ ), as opposed to pneumoperitoneum values during LTA (12 $\mathrm{mm} \mathrm{Hg}$ ). Taking into account the extensive exposition of inferior vena cava during right-sided PRA and the ratio of insufflation pressure to central venous pressure, we speculate that compression of the inferior vena cava may result in decreased glomerular filtration rate and possibly in decreased secretion by the distal tubules.

In the present study cystatin $\mathrm{C}$ concentrations in serum tended to follow creatinine changes; however, they did not reach statistical significance (Tab. II, Fig. 3). Nevertheless, cystatin C in our study showed a high positive correlation with creatinine levels, as assessed at day 1 postoperatively $(R=0.7)$. The fact might be partially explained by different effects of hypertensive drugs, especially those decreasing vascular resistance, which may cause factitious decrease in cystatin C [27, 28].

Earlier studies on renal function concentrated exclusively on patients with primary hyperaldosteronism, who underwent unilateral laparoscopic adrenalectomy [16-18]. The main factors predicting impaired kidney function postoperatively were preoperative eGFR $\leq 102 \mathrm{ml} / \mathrm{min} / 1.73 \mathrm{~m}^{2}$ and aldosterone to renin ratio $\geq 448 \mathrm{ng} / \mathrm{dl}: \mathrm{ng} / \mathrm{ml} / \mathrm{h}$ [29]. Utsumi et al. [18] claimed that laparoscopic adrenalectomy itself did not impair renal function but elicited preoperative renal damage masked by hyperfiltration. In our study only six patients $(7.8 \%)$ were treated for primary hyperaldosteronism. Similarly to other publications, our patients with aldosterone-producing adenoma had lower initial eGFR when compared to subjects with non-functioning incidentaloma $\left(72.3 \pm 9.0\right.$ vs. $102.1 \pm 8.9 \mathrm{ml} / \mathrm{min} / 1.73 \mathrm{~m}^{2}$; $\mathrm{p}<0.05)$. Postoperatively their urinary NGAL concentrations increased significantly as assessed at day 1 in comparison to initial levels $(\mathrm{p}<0.05)$ but returned to preoperative values within one month.

Interestingly, Kaga et al. [30] reported that hyperaldosteronism was also associated with new-onset dyslipidaemia postoperatively. Eighteen of 39 patients developed dyslipidaemia 12 months after laparoscopic adrenalectomy. The preoperative risk factors identified were: high body mass index (BMI) and decreased eGFR. Within our study group 37 out of 77 patients had BMI $>30 \mathrm{~kg} / \mathrm{m}^{2}$ and three of them had BMI $>40$ $\mathrm{kg} / \mathrm{m}^{2}$. This has not been the subject of this study; however, other publications demonstrate a close link between obesity, dyslipidaemia, metabolic syndrome, and other comorbidities [31-34]. The impact of hyperaldosteronism and high renin activity extends beyond cardiovascular system and renal function. The mechanisms involved in aldosterone production have also been linked via interleukin- 6 to mineral bone disorder [35-37]. 
Our study has several limitations. The patients included in the study are not homogenous in terms of clinical and pathological diagnoses; however, the differences between LTA and PRA groups are not significant. The groups are not of equal size - to avoid any selection bias, we decided to randomise all patients, without restraining the sizes of the groups. The study was not blinded, as it was not possible to keep the approach to adrenalectomy blind longer than for a few days. We did not measure the urine output of the patients. Finally, we could not eliminate the influence of medication on the obtained results (only 15 patients were free of any medication).

\section{Conclusions}

In this pioneering study we found increased concentrations of urinary NGAL at day 1 following laparoscopic adrenalectomy using PRA, as compared to LTA. Patients undergoing right-sided PRA had increased creatinine concentrations, as compared to left-sided PRA. We speculate that this association may result from compression of inferior vena cava by high retroperitoneal pressure during right-sided adrenalectomy by PRA. Even though the observed impairment of renal function has transient character, patients with high risk of acute kidney injury may benefit from adrenalectomy using LTA instead of PRA technique.

\section{Acknowledgements}

This work was supported by the Medical University of Bialystok (grant no. N/ST/ZB/17/001/1140).

\section{References}

1. Mansmann G, Lau J, Balk E, et al. The clinically inapparent adrenal mass update in diagnosis and management. Endocr Rev. 2004; 25(2): 309-340, doi: 10.1210/er.2002-0031, indexed in Pubmed: 15082524.

2. Szeliga J, Sondka Z, Jackowski M, et al. NOD2/CARD15 polymorphism in patients with rectal cancer. Med Sci Monit. 2008; 14(9): CR480-CR484 indexed in Pubmed: 18758419.

3. Kuklinski A, Kamocki Z, Koda M, et al. IGF-IR in patients with advanced colorectal cancer in correlation with certain clinico-morphological factors: Initial report. Oncol Lett. 2011; 2(6): 1155-1159, doi: 10.3892/ol.2011.396, indexed in Pubmed: 22848281.

4. Swiglo BA, Murad MH, Schünemann HJ, et al. A case for clarity, consistency, and helpfulness: state-of-the-art clinical practice guidelines in endocrinology using the grading of recommendations, assessment, development, and evaluation system. J Clin Endocrinol Metab. 2008; 93(3): 666-673, doi: 10.1210/jc.2007-1907, indexed in Pubmed: 18171699

5. Myśliwiec J, Zukowski L, Grodzka A, et al. Problems in diagnostics of primary aldosteronism - analysis of the own data. Endokrynol Pol. 2010; 61(1): 2-5, indexed in Pubmed: 20205097.

6. Myśliwiec J, Siewko K, Zukowski L, et al. Pheochromocytoma — analysis of 15 consecutive cases from one centre. Endokrynol Pol. 2013; 64(3): 192-196, indexed in Pubmed: 23873422.

7. Myśliwiec J, Rudy A, Siewko K, et al. [Diagnostic difficulties in adrenal incidentaloma - analysis of 125 cases]. Endokrynol Pol. 2007; 58(5): 17-421, indexed in Pubmed: 18058737.

8. Szeliga J, Jackowski M. Minimally invasive procedures in severe acute pancreatitis treatment - assessment of benefits and possibilities of use. Wideochir Inne Tech Maloinwazyjne. 2014; 9(2): 170-178, doi: 10.5114/wiitm.2014.41628, indexed in Pubmed: 25097683.

9. Piątkowski J, Jackowski M, Szeliga J. Laparoscopic surgery of esophageal hiatus hernia - single center experience. Wideochir Inne Tech Maloin- wazyjne. 2014; 9(1): 13-17, doi: 10.5114/wiitm.2014.40174, indexed in Pubmed: 24729804.

10. Tiberio GAM, Baiocchi GL, Arru L, et al. Prospective randomized comparison of laparoscopic versus open adrenalectomy for sporadic pheochromocytoma. Surg Endosc. 2008; 22(6): 1435-1439, doi: 10.1007/s00464-008-9904-1, indexed in Pubmed: 18398641.

11. Lee CR, Walz MK, Park S, et al. A comparative study of the transperitoneal and posterior retroperitoneal approaches for laparoscopic adrenalectomy for adrenal tumors. Ann Surg Oncol. 2012; 19(8): 2629-2634, doi: 10.1245/s10434-012-2352-0, indexed in Pubmed: 22526902.

12. Nigri G, Rosman AS, Petrucciani N, et al. Meta-analysis of trials comparing laparoscopic transperitoneal and retroperitoneal adrenalectomy. Surgery. 2013; 153(1): 111-119, doi: 10.1016/j.surg.2012.05.042, indexed in Pubmed: 22939744

13. Barczyński M, Konturek A, Nowak W. Randomized clinical trial of posterior retroperitoneoscopic adrenalectomy versus lateral transperitoneal laparoscopic adrenalectomy with a 5-year follow-up. Ann Surg. 2014; 260(5): 740-7; discussion 747, doi: 10.1097/SLA.0000000000000982, indexed in Pubmed: 25243546.

14. Myśliwiec P, Marek-Safiejko M, Lukaszewicz J, et al. Videoscopic adrenalectomy - when does retroperitoneal seem better? Wideochir Inne Tech Maloinwazyjne. 2014; 9(2): 226-233, doi: 10.5114/wiitm.2014.41636, indexed in Pubmed: 25097691.

15. Marek-Safiejko M, Safiejko K, Łukaszewicz J, et al. A Comparison of Two Approaches to Laparoscopic Adrenalectomy: Lateral Transperitoneal Versus Posterior Retroperitoneal Approach. Adv Clin Exp Med. 2016; 25(5): 829-835, doi: 10.17219/acem/62347, indexed in Pubmed: 28028944

16. Yoshioka M, Nakajima Y, Miyamoto T, et al. Age-Dependent Progression of Renal Dysfunction After Adrenalectomy for Aldosterone-Producing Adenomas in Japan. J Endocr Soc. 2019; 3(3): 577-589, doi: 10.1210/js.2018-00260, indexed in Pubmed: 30805569.

17. Onohara T, Takagi T, Yoshida K, et al. Assessment of postoperative renal function after adrenalectomy in patients with primary aldosteronism. Int J Urol. 2019; 26(2): 229-233, doi: 10.1111/iju.13844, indexed in Pubmed: 30384394.

18. Utsumi T, Kamiya N, Kaga M, et al. Development of novel nomogram to predict renal functional outcomes after laparoscopic adrenalectomy in patients with primary aldosteronism. World J Urol. 2017; 35(10): 1577-1583, doi: 10.1007/s00345-017-2033-5, indexed in Pubmed: 28401356.

19. Major P, Matłok M, Pedziwiatr M, et al. Do we really need routine drainage after laparoscopic adrenalectomy and splenectomy? Wideochir Inne Tech Maloinwazyjne. 2012; 7(1): 33-39, doi: 10.5114/wiitm.2011.25610, indexed in Pubmed: 23255998.

20. Abella V, Scotece M, Conde J, et al. The potential of lipocalin-2/NGAL as biomarker for inflammatory and metabolic diseases. Biomarkers. 2015; 20(8): 565-571, doi: 10.3109/1354750X.2015.1123354, indexed in Pubmed: 26671823

21. Liebetrau C, Gaede L, Doerr O, et al. Neutrophil gelatinase-associated lipocalin (NGAL) for the early detection of contrast-induced nephropathy after percutaneous coronary intervention. Scand J Clin Lab Invest. 2014; 74(2): 81-88, doi: 10.3109/00365513.2013.860615, indexed in Pubmed: 24304491.

22. Chapter 1: Definition and classification of CKD. Kidney Int Suppl. 2013 3(1): 19-62, doi: 10.1038/kisup.2012.64, indexed in Pubmed: 25018975.

23. Natkaniec M, Pędziwiatr M, Wierdak M, et al. Laparoscopic adrenalectomy for pheochromocytoma is more difficult compared to other adrenal tumors. Wideochir Inne Tech Maloinwazyjne. 2015; 10(3): 466-471, doi: 10.5114/wiitm.2015.52869, indexed in Pubmed: 26649097.

24. Pedziwiatr M, WierdakM, Ostachowski M, et al. Single center outcomes of laparoscopic transperitoneal lateral adrenalectomy — Lessons learned after 500 cases: A retrospective cohort study. Int J Surg. 2015; 20: 88-94, doi: 10.1016/j.ijsu.2015.06.020, indexed in Pubmed: 26074291.

25. Celik T, Altekin E, İsgüder R, et al. Evaluation of neutrophil gelatinase-associated lipocalin in pediatric patients with acute rotavirus gastroenteritis and dehydration. Ital J Pediatr. 2013; 39: 52, doi: 10.1186/1824-7288-39-52, indexed in Pubmed: 24004459.

26. Perrone RD, Madias NE, Levey AS. Serum creatinine as an index of renal function: new insights into old concepts. Clin Chem. 1992; 38(10): 1933-1953, indexed in Pubmed: 1394976.

27. Watanabe S, Okura T, Kurata M, et al. Valsartan reduces serum cystatin $C$ and the renal vascular resistance in patients with essential hypertension. Clin Exp Hypertens. 2006; 28(5): 451-461, doi: 10.1080/10641960600798671, indexed in Pubmed: 16820342

28. Salgado JV, Souza FL, Salgado BJ. How to understand the association between cystatin $C$ levels and cardiovascular disease: Imbalance, counterbalance, or consequence? J Cardiol. 2013; 62(6): 331-335, doi: 10.1016/j jjcc.2013.05.015, indexed in Pubmed: 23849291.

29. Kim IlY, Park IS, Kim MJ, et al. Change in kidney function after unilatera adrenalectomy in patients with primary aldosteronism: identification of risk factors for decreased kidney function. Int Urol Nephrol. 2018; 50(10): 1887-1895, doi: 10.1007/s11255-018-1887-9, indexed in Pubmed: 29779118 
30. Kaga M, Utsumi T, Tanaka T, et al. Risk of New-Onset Dyslipidemia After Laparoscopic Adrenalectomy in Patients with Primary Aldosteronism. World J Surg. 2015; 39(12): 2935-2940, doi: 10.1007/s00268-015-3197-z, indexed in Pubmed: 26296835.

31. Choromańska B, Myśliwiec P, Dadan J, et al. The clinical significance of fatty acid binding proteins. Postępy Hig Med Dośw. 2011; 65: 759-763, doi: 10.5604/17322693.966983, indexed in Pubmed: 22173440.

32. Choromańska B, Myśliwiec P, Razak Hady H, et al. Metabolic Syndrome is Associated with Ceramide Accumulation in Visceral Adipose Tissue of Women with Morbid Obesity. Obesity (Silver Spring). 2019; 27(3): 444-453, doi: 10.1002/oby.22405, indexed in Pubmed: 30724038

33. Myśliwiec H, Baran A, Harasim-Symbor E, et al. Increase in circulating sphingosine-1-phosphate and decrease in ceramide levels in psoriatic patients. Arch Dermatol Res. 2017; 309(2): 79-86, doi: 10.1007/s00403-016-1709-9, indexed in Pubmed: 27988894.
34. Choromańska K, Choromańska B, Dabrowska E, et al. Saliva of obese patients - is it different? Postepy Hig Med Dosw (Online). 2015; 69: 1190-1195, indexed in Pubmed: 26561845.

35. Donderski R, Stróżecki P, Sulikowska B, et al. Aldosterone antagonist therapy and its relationship with inflammation, fibrosis, thrombosis, mineral-bone disorder and cardiovascular complications in peritoneal dialysis (PD) patients. Int Urol Nephrol. 2017; 49(10): 1867-1873, doi: 10.1007/s11255-017-1655-2, indexed in Pubmed: 28710615.

36. Willenberg HS, Ansurudeen I, Schebesta K, et al. The endothelium secretes interleukin-6 (IL-6) and induces IL-6 and aldosterone generation by adrenocortical cells. Exp Clin Endocrinol Diabetes. 2008; 116(Suppl 1): S70-S74, doi: 10.1055/s-2008-1081497, indexed in Pubmed: 18777460.

37. Mysliwiec J, Zbucki R, Winnicka MM, et al. A crucial role of interleukin-6 in the pathogenesis of thyrotoxicosis-related disturbances of bone turnover in mice. Horm Metab Res. 2007; 39(12): 884-888, doi: 10.1055/s-2007-992776, indexed in Pubmed: 17973207. 